\title{
Bile Duct Injuries During Open and Laparoscopic Cholecystectomy
}

\author{
EL SAYED AHMED MOSTAFA, M.D.*; EMAD M. MOSTAFA, M.S.**; \\ HAMED AHMED ELBADAWY, M.D.* and MOHAMED ABD EL AAL MOHAMED, M.D.** \\ The Department of General Surgery, Faculty of Medicine for Girls, Al-Azhar University* and October 6 th University**, \\ Cairo, Egypt
}

\begin{abstract}
Background: Common Bile duct injury after cholecystectomy remains one of the most serious iatrogenic catastrophes associated with significant postoperative morbidity and may lead to death after a short period of systemic inflammatory response and multi-organ failure syndrome.
\end{abstract}

Aim of Study: To study the diagnosis and management of bile duct injuries during open and laparoscopic cholecystectomy, to avoid further bile duct injuries and its morbidity and mortality.

Patients and Methods: This Study was a prospective comparative study on iatrogenic bile duct injury (BDI) after laparoscopic and open cholecystectomy. The cases were performed in the period from April 2015 till February 2018. In which 40 patients with bile duct injuries, 20 after open cholecystectomy (OC) and 20 after laparoscopic cholecystectomy (LC) were managed.

Results: The number of cases done was 40 patients: 20 patients; $7(17.5 \%)$ males, $13(32.5 \%)$ females post laparoscopic cholecystectomy, Mean age was 44.3 while overall age range from $25-62$ years. 20 patient $9(22.5 \%)$ males, 11 $(27.5 \%)$ females post open cholecystectomy, Mean age was 42.2 while overall age range from $27-65$ years, Fifteen $(37.5 \%)$ of them associated with diabetes mellitus.

Management of BDI after open cholecystectomy was one conservatively, 14 by ERCP with stent, 3 by hepaticojejunostomy and 2 by Choledochojejunostomy. After laparoscopic cholecystectomy were managed 2 conservatively, 12 by ERCP and 6 by hepaticojejunostomy.

Conclusion: CBD injury complication with early diagnosis and prompt treatment can save patient's life with subsequent few or no complication even after its reconstructive surgery. Training must be emphasized to find all possible ways of recognizing biliary tract anatomy during surgery and possess skills to overwhelm the primary and leading cause of bile duct injury i.e. the visual misperception.

Key Words: Bile duct injury (BDI) - Laparoscopic cholecystectomy $(L C)$ - Open cholecystectomy $(O C)$.

Correspondence to: Dr. Emad M. Mostafa, Email: emadmostafa@hotmail.com

\section{Introduction}

COMMON Bile duct injury after cholecystectomy is remain one of the most serious iatrogenic catastrophes associated with significant postoperative morbidity and often leads to death after a short period of systemic inflammatory response syndrome and multi-organ failure syndrome [1] .

Reports have estimated that the incidence of BDI has risen from $0.2-0.4 \%$ for open cholecystectomy to $0.6-0.8 \%$ for $\mathrm{LC}$, but the true rate still remains unknown. There seems to be a trend to more complicated and proximal injuries (injury $<2 \mathrm{~cm}$ from the bifurcation) [2].

This injury is often overlooked and misbehaved by operating surgeon either because of disorientation of anatomical variables, or by inadvertent dissection at Calot's triangle or by visual misperception [3].

These injuries present at variable time after the primary surgery. The prompt recognition and active early management affects the morbidity and mortality associated with it [4] .

Avoidance of injury can be achieved by optimum exposure of Calot's triangle, judicious use of diathermy near territory of CBD, using 30 degree telescope, safe clip application without tenting of CBD and keeping in consideration the rule of thumb to prevent common bile duct injury [3] .

\section{Subjects and Methods}

This study was conducted in General Surgery Department, El Zahraa University Hospital and October 6 th University Hospital in the period between April 2015 and February 2018. The study included (40) patients presenting to the hospital with post cholecystectomy bile duct injures. 
- (20) Post-open cholecystectomy BDI.

- (20) Post-laparoscopic cholecystectomy BDI.

Informed consent was taken from all patients who accepted the management of bile duct injuries accordingly and the possibilities of post-operative consequences, confidentiality is assured of the personal data and medical information.

Inclusion criteria: All Patients with bile duct injuries presented after cholecystectomy whether open or laparoscopic will be included.

Exclusion criteria: CBD stones, Biliary tumors, Liver cirrhosis, Mirizzi syndrome.

All patients were subjected to thorough history and clinical examination focused on manifestation of post cholecystectomy BDI.

Full Blood Count, Prothrombin Time, Fasting blood sugar.

Liver function tests: ALT, AST, Bilirubin (Total and Direct), Alkaline Phosphatase, GGT.

Kidney function tests: Serum urea, Serum creatinine, $\mathrm{Na}+, \mathrm{K}+$.

Cardiopulmonary evaluation (ECG, Chest Xray and echocardiography if indicated).

Radiological: All patients will have pelviabdominal ultrasound to show any biliary tree dilatation and abdominal collection.

\section{C.T abdomen and pelvis MRCP (and or) ERCP.}

\section{Statistical analyses:}

All data were performed using the SPSS 10.0 software (SPSS Inc., Chicago, IL, USA). The normally distributed variables were compared using Student's $t$-test. The results are expressed as means \pm standard deviation, medians (minimum-maximum), or frequencies. Correlation coefficients were calculated to represent the strength between two quantitative variables. Chi-square test was used to determine the relationship between two qualitative variables and Wilcoxon's rank sum test for variable with continuous or ordinal distributions. $p$-value of $<0.05$ was considered statistical significance.

\section{Results}

The number of cases done was 40 patients with post cholecystectomy bile duct injury, either post open or laparoscopic cholecystectomy, after exclusion of patients with CBD stones, biliary tumors, liver cirrhosis, Mirizzi syndrome (Table 1).

Table (1): Socio-demographic data variables

\begin{tabular}{|c|c|c|}
\hline $\begin{array}{l}\text { Age }(Y): \\
\quad \text { Range } \\
\quad \text { Mean } \pm \mathrm{SD}\end{array}$ & \multicolumn{2}{|c|}{$\begin{array}{c}25-65 \\
43.25 \pm 10.3\end{array}$} \\
\hline & No. & $\%$ \\
\hline $\begin{array}{l}\text { Sex: } \\
\qquad \begin{array}{l}\text { Male } \\
\text { Female }\end{array}\end{array}$ & $\begin{array}{l}16 \\
24\end{array}$ & $\begin{array}{l}40 \\
60\end{array}$ \\
\hline $\begin{array}{l}\text { Associated D.M: } \\
\text { Yes } \\
\text { No }\end{array}$ & $\begin{array}{l}15 \\
25\end{array}$ & $\begin{array}{l}37.5 \\
62.5\end{array}$ \\
\hline
\end{tabular}

Table (1) illustrates that total 40 patients; 16 (40\%) males and 24 (60\%) females were admitted due to post cholecystectomy bile duct injuries (Fig. 1). Fifteen $(37.5 \%)$ of them associated with diabetes mellitus (Fig. 2).

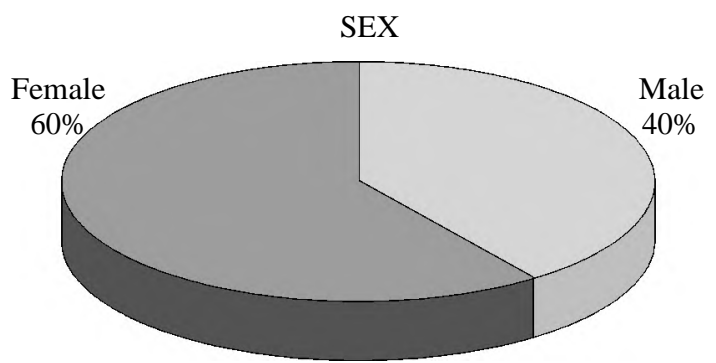

Fig. (1): Variation in sex in patient presented by post cholecystectomy BDI.

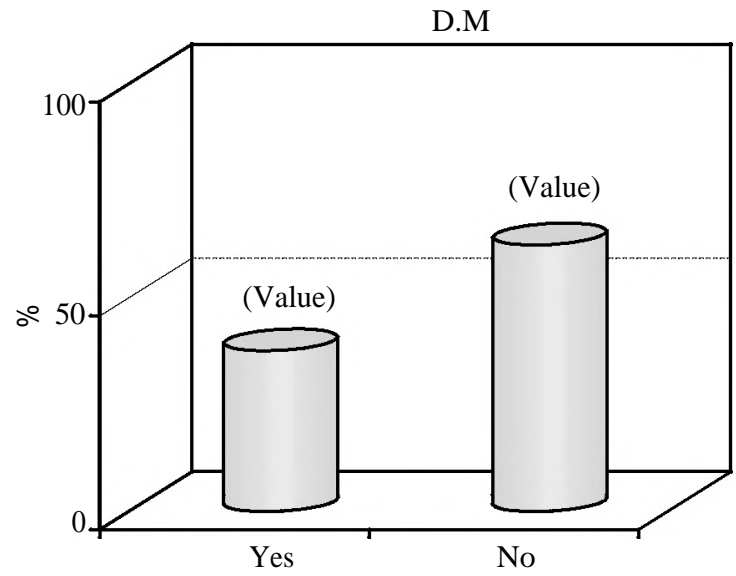

Fig. (2): Percentage of diabetic patient. 
Table (2): Comparison between the groups regarding socio-demographic data.

\begin{tabular}{|c|c|c|c|c|c|}
\hline Variables & $\begin{array}{c}\text { Open } \\
\text { cholecystectomy } \\
(\mathrm{N}=20) \%\end{array}$ & $\begin{array}{c}\text { Laparoscopic } \\
\text { Cholecystectomy } \\
(\mathrm{N}=20) \%\end{array}$ & Test & $\begin{array}{c}p- \\
\text { value }\end{array}$ & $\begin{array}{c}\text { OR \& } \\
(95 \% \mathrm{CI})\end{array}$ \\
\hline $\begin{array}{l}\text { Age: } \\
\quad \text { Mean } \pm \text { SD }\end{array}$ & $42.2 \pm 10.7$ & $44.3 \pm 10$ & $* t=-0.64$ & $>0.05$ & CI $(-8.7-4.5)$ \\
\hline $\begin{array}{l}\text { Sex: } \\
\quad \text { Male } \\
\quad \text { Female }\end{array}$ & $\begin{array}{l}9(45) \\
11(55)\end{array}$ & $\begin{array}{l}7(35) \\
13(65)\end{array}$ & $* X^{2}=0.42$ & $>0.05$ & $\begin{array}{l}\text { OR }(\text { Male/Female }) \\
=1.5 \\
\text { CI }(0.43-5.42)\end{array}$ \\
\hline $\begin{array}{l}\text { D.M: } \\
\text { Yes } \\
\text { No }\end{array}$ & $\begin{array}{l}9(45) \\
11(55)\end{array}$ & $\begin{array}{l}6(30) \\
14(70)\end{array}$ & $X^{2}=0.96$ & $>0.05$ & $\begin{array}{l}\text { OR }(\text { Yes/No) } \\
=1.9 \\
\text { CI }(0.5-7)\end{array}$ \\
\hline
\end{tabular}

Table (2) illustrates that there is no statistically significance difference with $p$-value $>0.05$ between post-open cholecystectomy BDI and postlaparoscopic BDI as regards to age, sex, and associated diabetes mellitus which indicates proper matching between the two groups.

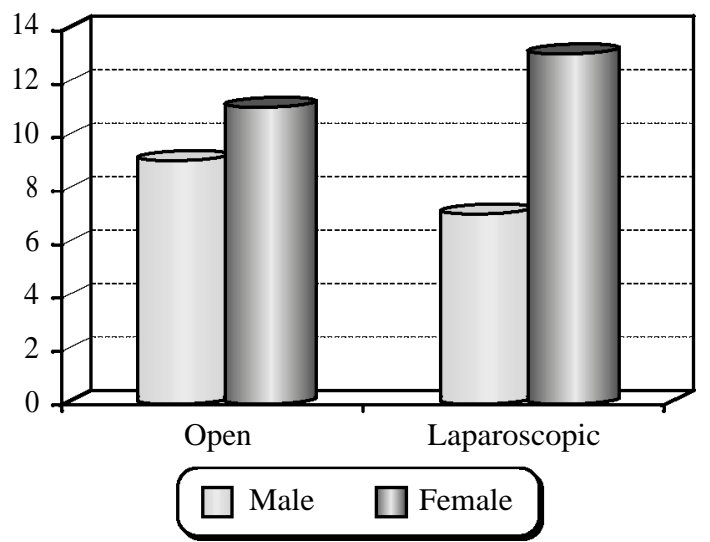

Fig. (3): Male to female ratio in post-open \& laparoscopic cholecystectomy BDI.

20 patients; 7 (17.5\%) males, 13 (32.5\%) females post laparoscopic cholecystectomy, Mean age was 44.3 while overall age range from $25-62$ years. 20 patient $9(22.5 \%)$ males, $11(27.5 \%)$ females post open cholecystectomy, Mean age was 42.2 while overall age range from 27-65 years (Fig. 3).

Table (3): Comparison between the groups regarding precholecystectomy morbidities.

\begin{tabular}{|c|c|c|c|c|}
\hline \multirow{2}{*}{ Techniques } & \multicolumn{2}{|c|}{ Acute attack } & \multirow{2}{*}{$\begin{array}{lc}\mathrm{X}^{2}- & p- \\
\text { test value }\end{array}$} & \multirow{2}{*}{$\begin{array}{c}\text { OR \& } \\
(95 \% \mathrm{CI})\end{array}$} \\
\hline & Yes & No & & \\
\hline $\begin{array}{l}\text { Open } \\
\text { cholecystectomy }\end{array}$ & $9(64.3)$ & $11(42.3)$ & \multirow{2}{*}{$1.76>0.05$} & \multirow{2}{*}{$\begin{array}{l}\text { OR } \\
\text { (open/lap.) } \\
=2.5 \\
\text { CI } \\
(0.64-9.3)\end{array}$} \\
\hline $\begin{array}{l}\text { Laparoscopic } \\
\text { Cholecystectomy }\end{array}$ & $5(35.7)$ & $15(57.7)$ & & \\
\hline
\end{tabular}

(Table 3) illustrates that there is no statistically significance difference with $p$-value $>0.05$ between pre-open cholecystectomy and pre-laparoscopic cholecystectomy as regards to acute attack of Cholecystitis. 14 patients (35\%) have history suggestive of acute Cholecystitis prior to cholecystectomy.

Table (4): Comparison between the groups regarding postcholecystectomy BDI.

\begin{tabular}{lcc}
\hline BDI & $\begin{array}{c}\text { Open } \\
\text { cholecystectomy } \\
(\mathrm{N}=20) \%\end{array}$ & $\begin{array}{c}\text { Laparoscopic } \\
\text { cholecystectomy } \\
(\mathrm{N}=20) \%\end{array}$ \\
\hline CD leak & $9(45 \%)$ & $9(45 \%)$ \\
CHD leak & $1(5 \%)$ & $3(15 \%)$ \\
CBD leak & $5(25 \%)$ & $1(5 \%)$ \\
CHD stenosis & $1(5 \%)$ & $5(25 \%)$ \\
CBD stenosis & $4(20 \%)$ & $2(10 \%)$ \\
\hline
\end{tabular}

Table (4) illustrate the different site of bile duct injuries after either open cholecystectomy or laparoscopic cholecystectomy, it is clear that injuries following open cholecystectomy tends to be at lower levels than injuries result after laparoscopic cholecystectomy.

Leak from cystic duct represent 18 cases 9 after open and 9 after laparoscopic cholecystectomy, leak from CHD represent 4 cases, leak from CBD present in 6 cases, while obstruction of CHD presents in 6 cases and obstruction of CBD in 6 cases Fig (4). 


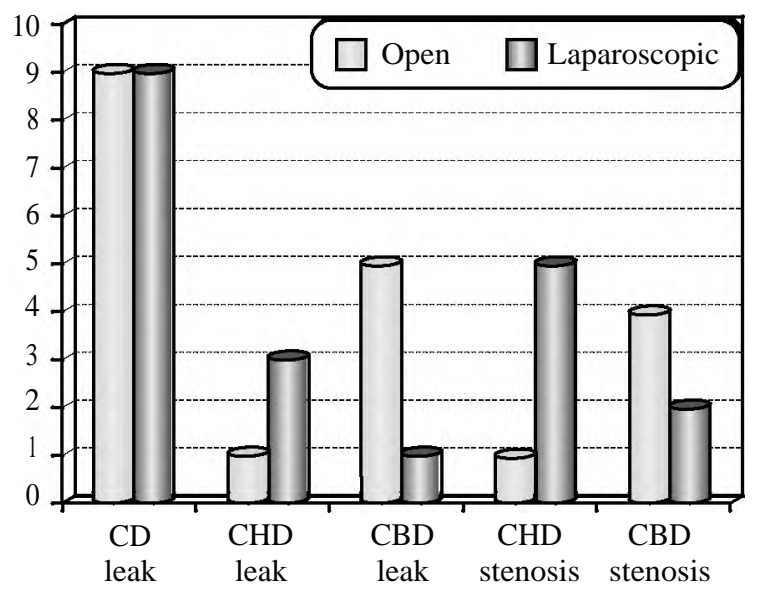

Fig. (4): Comparison between the groups regarding postcholecystectomy BDI.

Table (5): Comparison between the groups regarding postcholecystectomy US findings.

\begin{tabular}{lcccc}
\hline $\begin{array}{l}\text { US } \\
\text { findings }\end{array}$ & $\begin{array}{c}\text { Open } \\
\text { cholecystectomy } \\
(\mathrm{N}=20) \%\end{array}$ & $\begin{array}{c}\text { Laparoscopic } \\
\text { cholecystectomy } \\
(\mathrm{N}=20) \%\end{array}$ & $\begin{array}{c}\mathrm{X}^{2}- \\
\text { test }\end{array}$ & $\begin{array}{c}p \text { - } \\
\text { value }\end{array}$ \\
\hline $\begin{array}{l}\text { Collection } \\
\text { Bile duct } \\
\text { dilatation }\end{array}$ & $\begin{array}{c}15(75 \%) \\
5(25 \%)\end{array}$ & $\begin{array}{l}13(65 \%) \\
7(35 \%)\end{array}$ & $0.00>0.05$ \\
\hline
\end{tabular}

(Table 5) illustrates that there is no statistically significance difference with $p$-value $>0.05$ between post-open cholecystectomy and post-laparoscopic cholecystectomy as regards to ultrasound finding.

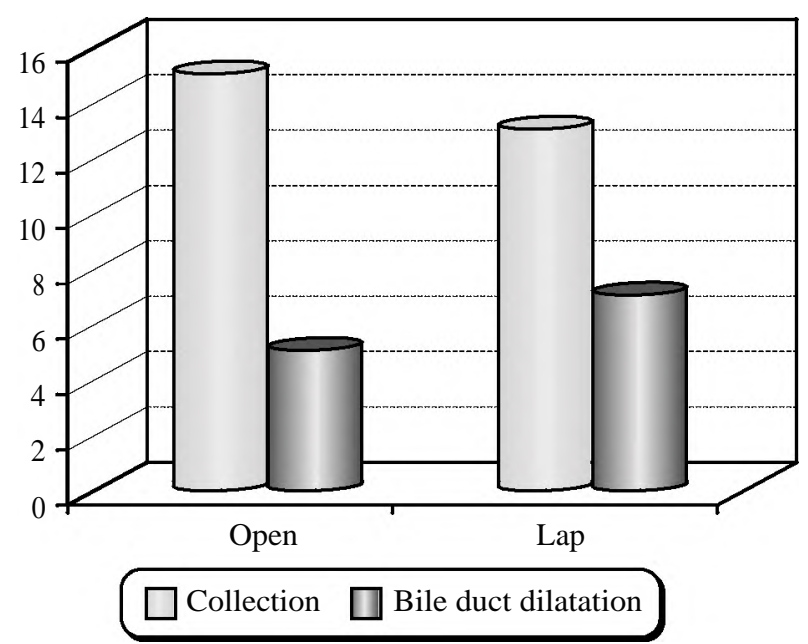

Fig. (5): Post-cholecystectomy ultrasound finding.

Post cholecystectomy bile duct injuries patients had been investigated by ultrasound imaging which demonstrates intra-abdominal collection in 28 patients (15 after open and 13 after laparoscopic cholecystectomy), and bile duct dilatation in 12 patients ( 5 after open and 7 after laparoscopic cholecystectomy. Fig. (5).
Table (6): Correlation between post-cholecystectomy bile duct diameter and laboratory findings.

\begin{tabular}{|c|c|c|c|c|}
\hline $\begin{array}{l}\text { Lab. } \\
\text { Findings }\end{array}$ & $\begin{array}{l}\text { Post-Open } \\
\text { cholecy- } \\
\text { stectomy } \\
\text { Bile Duct } \\
\text { diameter } \\
(r)\end{array}$ & $\begin{array}{c}p- \\
\text { value }\end{array}$ & $\begin{array}{c}\text { Post- } \\
\text { Laparoscopic } \\
\text { Cholecystectomy } \\
\text { Bile Duct } \\
\text { diameter }(r)\end{array}$ & $\begin{array}{c}p \text { - } \\
\text { value }\end{array}$ \\
\hline SGPT (U/L) & 0.304 & $>0.05$ & 0.337 & $>0.05$ \\
\hline $\begin{array}{l}\text { Alkaline } \\
\text { phosphatas } \\
\text { (U/L) }\end{array}$ & 0.605 & $*<0.05$ & 0.381 & $>0.05$ \\
\hline GGT (U/L) & 0.546 & $*<0.05$ & 0.432 & $>0.05$ \\
\hline $\begin{array}{l}\text { Total bilirubin } \\
(\mathrm{mg} / \mathrm{dl})\end{array}$ & 0.695 & $*<0.05$ & 0.482 & $*<0.05$ \\
\hline $\begin{array}{l}\text { Direct bilirubin } \\
(\mathrm{Mg} / \mathrm{dl})\end{array}$ & 0.652 & $*<0.05$ & 0.421 & $>0.05$ \\
\hline
\end{tabular}

(Table 6) illustrates that there is no statistically significance difference with $p$-value $>0.05$ as a correlation between post-open cholecystectomy CBD diameter and SGPT but there is a statistically significance difference with $p$-value $<0.05$ as regard correlation between CBD diameter and alkaline phosphatase, GGT, total and direct bilirubin.

Table illustrate that there is no statistically significance difference with $p$-value $>0.05$ as a correlation between post-laparoscopic cholecystectomy CBD diameter and SGPT, GGT, alkaline phosphatase and direct bilirubin but there is a statistically significance difference with $p$-value $<0.05$ as regard correlation between CBD diameter and GGT, total bilirubin.

As regard CBD diameter in Patient presented post laparoscopic cholecystectomy BDI the Mean diameter was $10.2 \mathrm{~mm}$ while overall diameter range from (6-19) $\mathrm{mm}$, while post open cholecystectomy BDI the Mean diameter was $10.35 \mathrm{~mm}$ while overall diameter range from (6-18) $\mathrm{mm}$.

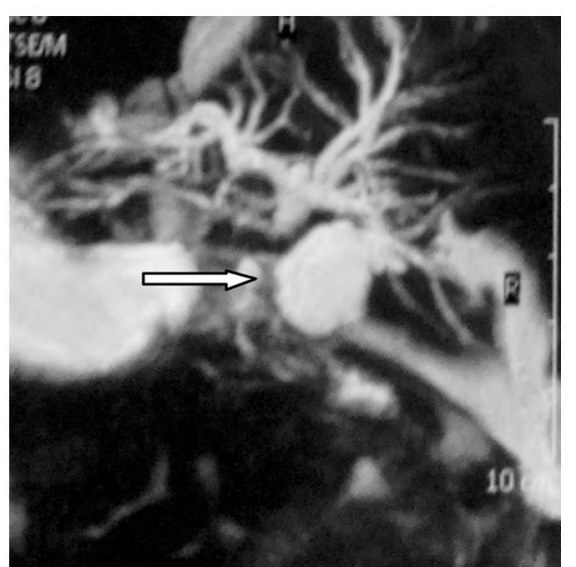

Fig. (6): MRCP after open cholecystectomy showing CHD dilatation, proximal part of CBD (white arrow) is not seen (ligated) with normal distal part and mild perihepatic collection. 
Patients presented in time interval between prior surgery and onset of symptoms after getting biliary injury complication were $23(57.5 \%) \mathrm{im}$ mediate post-operative, 15 (37.5\%) within one month, $2(5 \%)$ in 6 months.

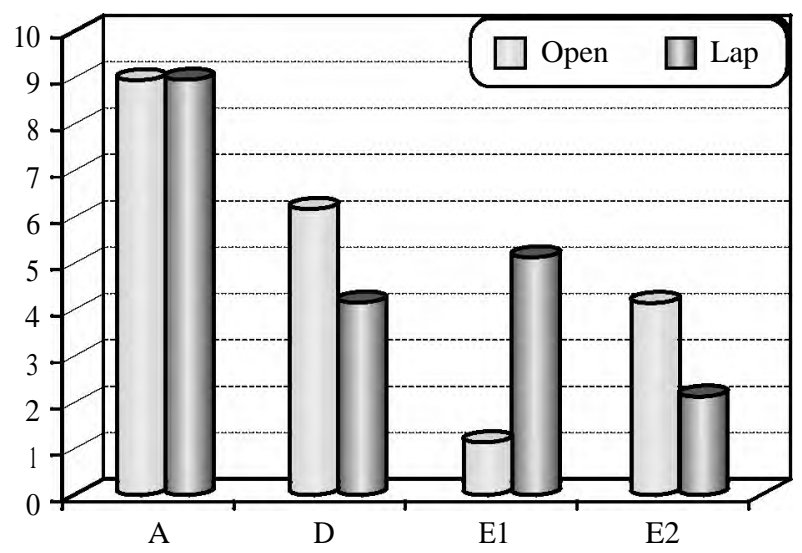

Fig. (7): Types of BDI according to Strasburg $(n=40)$.

This figure shows the classification of patients presented by iatrogenic bile duct injuries according to Strasburg classification.

Table (7): Type of management of patients with post cholecystectomy bile duct injuries $(n=40)$.

\begin{tabular}{lcl}
\hline Management of BDI & Number & $\%$ \\
\hline Conservative management & 3 & 7.5 \\
ERCP & 26 & 65 \\
Reconstructive surgery & 11 & 27.5 \\
\hline
\end{tabular}

Table (7) illustrate the percentage of type of management of post cholecystectomy bile duct injuries which includes conservative management without ERCP only in 3 patients, ERCP with stent in 26 patients and reconstructive surgery in 11 patients (Fig. 8).

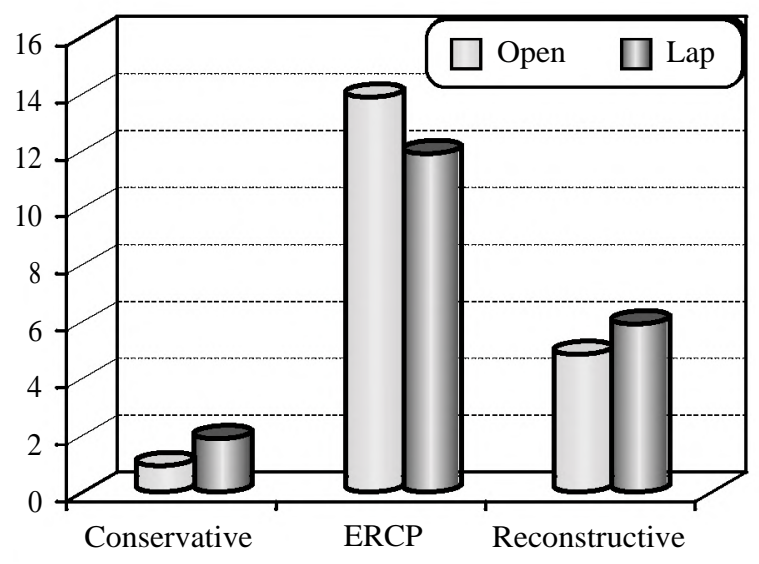

Fig. (8): Shows type of management of patients with post cholecystectomy BDI $(n=40)$.
Table (8): Comparison between the two groups regarding post-cholecystectomy BDI management.

\begin{tabular}{lcc}
\hline Management & $\begin{array}{c}\text { Open } \\
\text { cholecystectomy } \\
(\mathrm{N}=20) \%\end{array}$ & $\begin{array}{c}\text { Laparoscopic } \\
\text { cholecystectomy } \\
(\mathrm{N}=20) \%\end{array}$ \\
\hline Conservative & $1(5)$ & $2(10)$ \\
ERCP & $14(70)$ & $12(60)$ \\
Hepatico jejonostomy & $3(15)$ & $6(30)$ \\
Choledocho jejonostomy & $2(10)$ & $0(0)$ \\
\hline
\end{tabular}

This Table (13) illustrates that Total 26 patients underwent ERCP after prior cholecystectomy 14 after open and 12 after laparoscopic cholecystectomy.

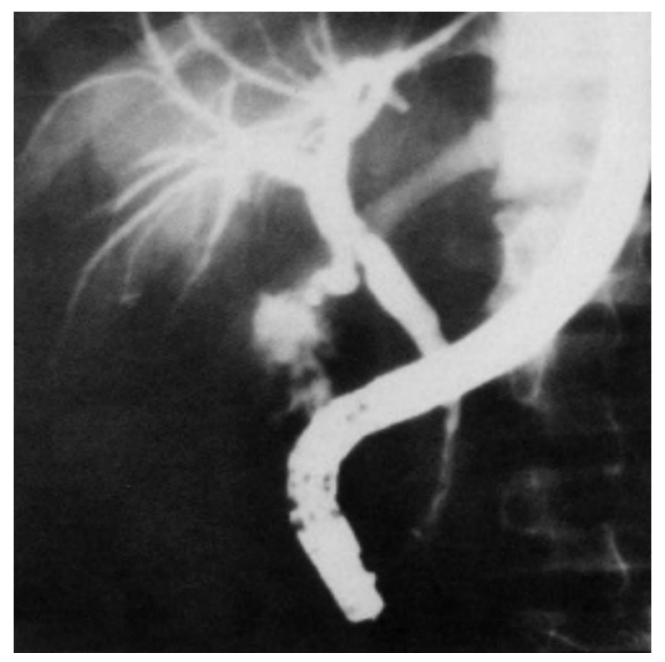

Fig. (9): ERCP showing leak from common bile duct following laparoscopic cholecystectomy. Note remnant cystic duct stump filling above leakage site. Subsequent stent placement has been done.

Five patients were found with narrowing in proximal CBD after open cholecystectomy and 3 after laparoscopic cholecystectomy which was dilated and stented with sphincterotomy.

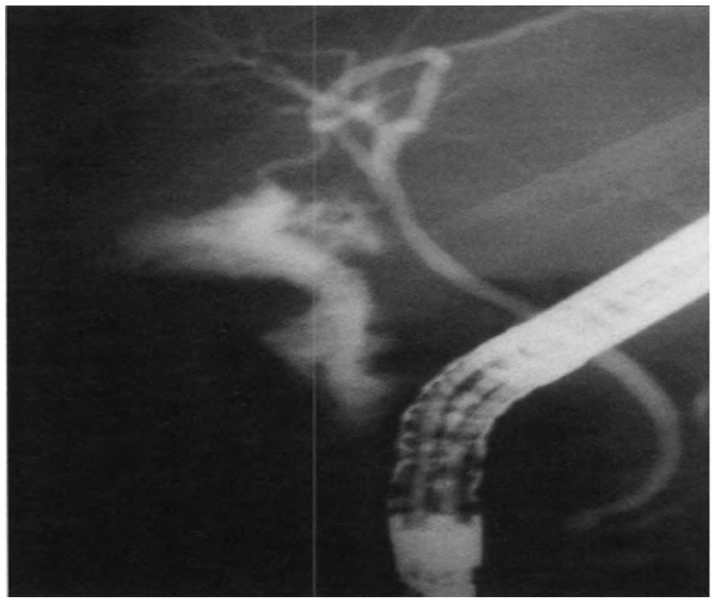

Fig. (10): ERCP showing leak from cystic duct remnant, stent placement was done. 
Nine patients presented with minor biliary leakage from cystic duct stump after open cholecystectomy and nine after laparoscopic cholecystectomy which was stented as well (Fig. 10).

Reconstructive surgery was performed in total 11 patients, 5 after open cholecystectomy and 6 after laparoscopic cholecystectomy 9 got smooth $\&$ uneventful recovery, and 1 patient developed intra-abdominal collection which was drained percutaneous under ultra sound guidance and another underwent redo hepaticojejunostomy (Fig. 11).

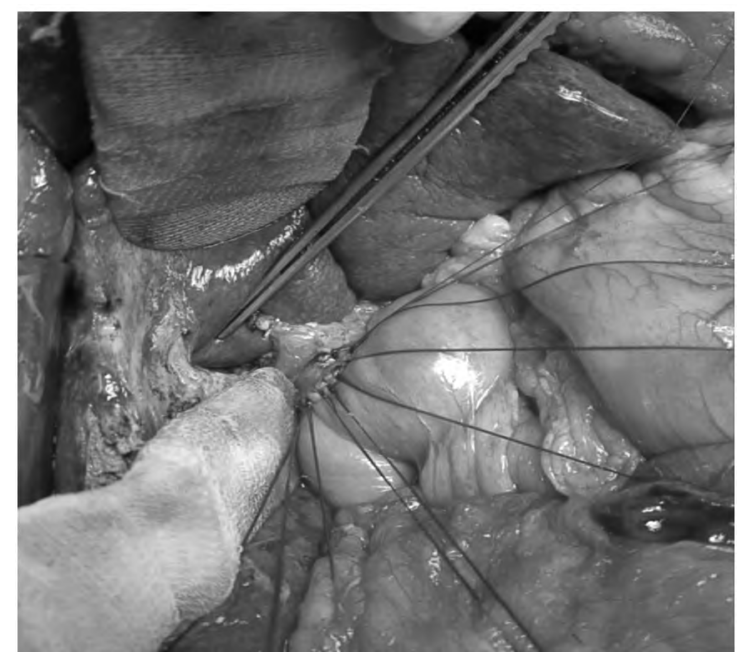

Fig. (11): Hepaticojejunostomy for management of BDI after laparoscopic cholecystectomy.

6 patients $(15 \%)$ presented by bile duct injury after laparoscopic cholecystectomy who need reconstructive surgery had been done by hepaticojejunostomy as all of them acquired high level injury of bile duct.

On the other hand 5 patient $(12.5 \%)$ presented by bile duct injury after open cholecystectomy who need reconstructive surgery $3(7.5 \%)$ of them had been done by hepaticojejunostomy and $2(5 \%)$ had been done by Choledochojejunostomy.

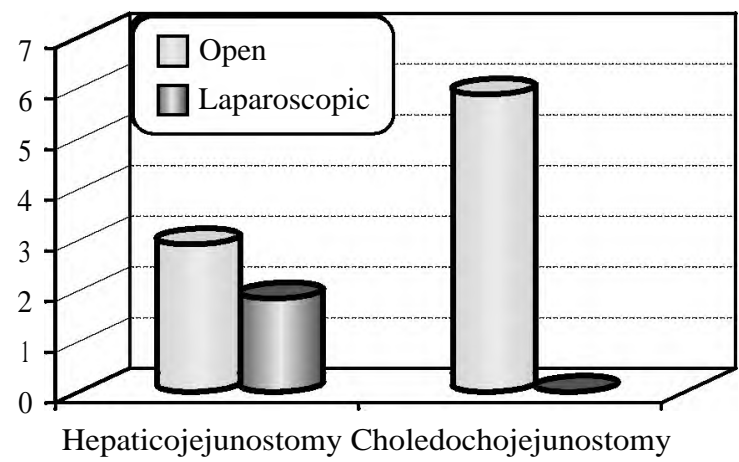

Fig. (12): Type of reconstruction after open and laparoscopic BDI.
Table (9): Management according to presentation

\begin{tabular}{lcccc}
\hline & \multicolumn{2}{c}{$\begin{array}{c}\text { Leak }(\mathrm{n}=28) \\
(70 \%)\end{array}$} & \multicolumn{2}{c}{$\begin{array}{c}\text { Stenosis }(\mathrm{n}=12) \\
(30 \%)\end{array}$} \\
\cline { 2 - 5 } Management & Open & Lap & Open & Lap \\
& $\mathrm{N}=15$ & $\mathrm{~N}=13$ & $\mathrm{~N}=5$ & $\mathrm{~N}=7$ \\
\hline Conservative & 1 & 2 & 0 & 0 \\
ERCP & 12 & 9 & 2 & 3 \\
Choledochojejunostomy & 1 & 0 & 1 & 0 \\
Hepaticojejunostomy & 1 & 2 & 2 & 4 \\
\hline
\end{tabular}

Table (9) shows the different management of bile duct injuries following either leak or stenosis after open and laparoscopic cholecystectomy, 15 patients presented by biliary leakage after open cholecystectomy, one of them managed conservatively, 12 patients by ERCP, one patient by Choledochojejunostomy and the last one by hepaticojejunostomy.

13 patients presented by biliary leakage after laparoscopic cholecystectomy, two of them managed conservatively, 9 patients by ERCP, and the last one by hepaticojejunostomy, 5 patients presented by biliary stenosis after open cholecystectomy, 2 patients managed by ERCP, one patient by Choledochojejunostomy and 2 patients by hepaticojejunostomy, 7 patients presented by biliary stenosis after laparoscopic cholecystectomy, 3 patients managed by ERCP and 4 patients managed by hepaticojejunostomy, Patients with Postcholecystectomy bile duct injuries who required biliary duct reconstructive surgery their Operative duration during reconstructive surgery (Choledochojejunostomy or hepaticojejunostomy) was (mean \pm SD) $(233 \pm 19)$ minutes.

Table (10): Follow-up after management of BDI.

\begin{tabular}{lllll}
\hline Procedure & No. & $\%$ & Follow-up & Management \\
\hline Conservative & 3 & 7.5 & Uneventful & - \\
$\begin{array}{l}\text { ERCP } \\
\begin{array}{c}\text { Hepatico- } \\
\text { jejunostomy }\end{array}\end{array}$ & 9 & 65 & $\begin{array}{c}\text { Uneventful } \\
1 \text { anastomotic } \\
\text { leak }\end{array}$ & 1 Redo \\
$\begin{array}{c}\text { Choledocho- } \\
\text { jejunostomy }\end{array}$ & 2 & 5 & $\begin{array}{c}\text { 1 collection } \\
\text { US guided } \\
\text { drainage }\end{array}$ \\
\hline
\end{tabular}

(Table 10) shows 6 months follow-up after management of bile duct injuries following cholecystectomy (open or laparoscopic), three (7.5\%) patients managed by conservative treatment in whom intra-abdominal drain was remained for 2 weeks after cholecystectomy with consecutive decrease in amount on daily basis, with uneventful 6 months follow-up.

Another $26(65 \%)$ patient presented by leakage from cystic duct with no distal common bile duct 
obstruction, these patients managed by endoscopic retrograde cholangiopancreatography (ERCP), with uneventful 6 months follow-up.

Nine $(22.5 \%)$ patients managed by hepaticojejunostomy, one patient of them develop bile duct leak 5 days post-operative, he underwent redo surgery, Two (5\%) patients managed by Choledochojejunostomy, one patient develop intraabdominal collection after removal of intraabdominal drain, this patient managed by ultrasound guided aspiration.

\section{Discussion}

Cholecystectomy is one of the most common surgical procedures in the world, especially laparoscopic type. Although the incidence of iatrogenic bile duct injury (IBDI) is decreasing due to improvement in the learning curve and standardization of the procedure, it remains one of major issues that are facing us as surgeons [5].

Despite the popularity and wide use of laparoscopic cholecystectomy, the rate of serious complications with LC remains higher than seen with open cholecystectomy. One of the most serious intraoperative complications is common bile duct injury (CBDI), treatment of which may require additional procedures ranging from ERCP to surgical reconstruction and even liver transplantation. Previously, a $0.1-0.25 \%$ rate of CBDI was cited for open surgery; however, the rate of CBDI is generally acknowledged to be higher in LC. Various sources cite different rates of bile duct injury in LC, ranging from $0.3 \%$ to as high as $2.6 \%$ using NSQIP data [6].

BDI in this study it was equal during open cholecystectomy and laparoscopic cholecystectomy i.e. $20(50 \%)$ patient post-open cholecystectomy bile duct injuries and $20(50 \%)$ as compared to post-laparoscopic cholecystectomy; the reason behind this may be that most patients were referred from primary care hospital where still open cholecystectomy is performed by junior Surgeons.

A retrospective analysis of the Nationwide Inpatient Sample from 1998 to 2006 was performed with an inclusion criterion of cholecystectomy performed on hospital day 0 or 1 . Patient- and hospital-level factors potentially associated with bile duct injury were examined by logistic regression. A total of 377,424 cholecystectomy patients were identified. There were 1124 bile duct injuries $(0.30 \%)$, with $177(0.06 \%)$ in the laparoscopic cholecystectomy group and $947(1.46 \%)$ in the open cholecystectomy group $(p<.001)$. On multivariate analysis, significant risk factors for bile duct injury were male gender, age $>60$ years, and academic hospital status. Laparoscopic cholecystectomy, obesity, insurance status, or hospital volume was not associated with an increased risk of bile duct injury [7]

Our study including 40 patients presented by bile duct injury after cholecystectomy male gender representing $40 \%(n=16)$ and female patients representing $60 \%(n=24)$ and that is due to high rate of cholecystectomy performed in female patient due to high incidence of gall stone in female patients.

This study gives comparable result with the above studies where $26(65 \%)$ patient presented by leakage from cystic duct with no distal common bile duct obstruction, these patients managed by endoscopic retrograde cholangiopancreatography (ERCP), with uneventful 6 months follow-up.

In another study, 87 patients were managed initially by either balloon dilatation $(\mathrm{N}=28)$ or surgical reconstruction $(\mathrm{N}=59)$. Ten patients have not completed treatment and still have biliary stents in place. Evaluation of 25 patients completing treatment after balloon dilatation (mean followup, 27.8 months) showed a success rate of $64 \%$. Evaluation of 52 patients completing treatment after surgical reconstruction (mean follow-up, 33.4 months) showed a success rate of $92 \%$. All failures were managed successfully by either surgical reconstruction or balloon dilatation. Major bile duct injuries can be managed successfully by combined surgical and radiologic techniques. This series provides, for the first time, significant follow-up on a large number of patients with overall success rates of $64 \%$ after balloon dilatation and $92 \%$ after surgical reconstruction. The combination of surgery and balloon dilatation resulted in a successful outcome in $100 \%$ of patients treated [8].

This study gives comparable result with the above studies where 5 patients presented by biliary stenosis after open cholecystectomy, 2 patients managed by ERCP, one patient by Choledochojejunostomy and 2 patients by hepaticojejunostomy. 7 patients presented by biliary stenosis after laparoscopic cholecystectomy, 3 patients managed by ERCP and 4 patients managed by hepaticojejunostomy.

In one large series of post laparoscopic bile duct injuries revealed the primary cause of error in $97 \%$ of cases as a visual perceptual illusion. Faults in technical skills were present in only $3 \%$ of injuries, in another study it is reported that BDI more often than not occurs due to an error in 
perception rather than due to lack of knowledge, skills or judgment. The cognitive misperception of anatomy is so compelling that injuries are seldom recognized at the time of surgery and operation may be thought to be normal [9]

In this study, acute Cholecystitis in primary operation was relevant in $35 \%$ of patient $\mathrm{m}$ third add risk for visual misperception and difficulty in dissection of Calot's triangle and viewing the critical view of safety.

The final choice of treatment depends upon the type of injury. Usually, when the bile duct has not lost its continuity and the patient does not suffer from severe episodes of cholangitis, more conservative options such as percutaneous drainage or endoscopic stenting are preferred [10].

Alternatively, in cases of complete transection or in the presence of severe symptoms, surgical reconstruction is the treatment of choice. Some cases may even require hepatectomy as the last resort of treatment. Indications for this form of treatment include early (within 5 weeks after LC) vascular injury, proximal BDI, injury to the right hepatic artery, and sepsis caused by liver necrosis or bile duct necrosis. With more chronic patients (over 4 months after LC) hepatectomy effectively manages recurrent cholangitis and liver atrophy [11].

In iatrogenic bile duct injuries, It must be emphasized that preoperative cholangiography is mandatory in order to obtain an accurate image of the biliary tree. In cases in which the bile duct has been transected, a percutaneous transhepatic cholangiography will correctly predict the anatomic location of injuries in $85 \%$ of patients. This is not the case as far as intraoperative cholangiography (IOC) during LC is concerned, because literature is inconclusive or equivocal on this [12]

Preoperative cholangiography of patient presented by bile duct injuries had been done prior to reconstructive surgery, all of them had been done by ERCP, after imaging of them by MRCP.

Patients that presented by minor biliary leakage, ERCP was diagnostic and therapeutic in which stent is traversing the site of leakage.

Long-term outcomes in biliary reconstruction are mainly influenced by the level of injury, presence of local inflammation, timing of final repair, type of reconstruction, and experience and expertise of surgeon in these operations and previous attempts of repairs in the same or in other institutions.
Patients without history of previous interventions, lack of inflammation, lack of complete transection of common bile duct, and greater diameter of bile duct present better operative results, decreased rates of morbidity and mortality, and lower rates of postoperative complications [13] .

It is widely accepted that the best results in biliary reconstruction can be achieved in specialized hepatobiliary centers. Nevertheless, many general surgeons without previous experience attempt to repair these injuries, often without proper understanding or characterization of the biliary injury. This may be associated with inferior short-term and long-term outcomes, substantial morbidity, and higher rates of complications [12]

This study gives comparable result with the above studies where visual misperception might be recognized as a primary cause of presented bile duct injury as detailed below. 28 patients with biliary leakage 3 of them treated with hepaticojejunostomy, one of them treated with Choledochojejunostomy, 21 of them treated by ERCP and 3 of them managed conservatively.

Twelve patients were found bile duct stenosis at different levels six of them treated with hepaticojejunostomy, one of them treated by Choledochojejunostomy, and five of them treated with ERCP.

All developed smooth recovery except two patients, one developed intra-abdominal collection which was drained under ultrasound guidance by pigtail drain; another patient developed intraabdominal collection as a result of leak from anastomotic site of hepaticojejunostomy which was treated by hepaticojejunostomy.

Some injuries are remain unrecognized for many years, occasionally coming to light only when the patient develops secondary biliary cirrhosis but no such complication had been found in this study [14].

Reported in their study that operative success rate was $75 \%$ with $25 \%$ mortality which was related to the presence of peritonitis, development of multiorgan failure and late repair of bile duct injury. Study biased by short term follow-up for long term complications either of biliary tract stricture formation or development of liver cirrhosis [15]

Surgical procedures performed within the biliary tract are very common. The incidence of IBDI has increased recently, and has been associated with increased use of laparoscopic cholecystectomy 
worldwide. It is essential to be careful in the proper visualization of the surgical area and the identification of structures before ligation or transection in order to decrease the risk of bile duct injuries during surgery. When biliary injury develops, early recognition and appropriate treatment are most important. Early and correct treatment allows avoidance of serious complications in patients with IBDI. Following bile duct repair, patients require long term and careful postoperative observation because of the possibility of biliary anastomosis stricture.

Our operative success rate was $81.8 \%$ which includes 7 patients underwent hepaticojejunostomy and 2 patients underwent Choledochojejunostomy with smooth postoperative recovery course.

Morbidity was $18.9 \%$ which was related to development of leak following hepaticojejunostomy after post laparoscopic cholecystectomy bile duct injury and has been managed by redo hepaticojejunostomy, and another patient managed by ultrasound guided aspiration. Mortality rate was zero.

\section{Conclusion:}

CBD injuries if managed with early diagnosis and prompt treatment can save the patient's life with subsequent few or no complication even after its reconstructive surgery. Training must be emphasized to find all possible ways of recognizing biliary tract anatomy during surgery and to possess skills to overwhelm the primary and leading cause of bile duct injury i.e. the visual misperception.

Iatrogenic injuries to the biliary tree are uncommon, but remain a significant cause of morbidity following laparoscopic or open cholecystectomy. They present diagnostic and therapeutic challenges to the clinician, which vary with how and when the injuries are declared. If an iatrogenic bile duct injury is recognized at the time of surgery, immediate discussion with a hepatopancreatobiliary surgeon can help determine the most appropriate way to proceed. For those diagnosed postoperatively, multimodal management is best, each patient being discussed by a specialist multidisciplinary team.

\section{References}

1- MOORE D.E., FEURER I.D., HOLZMAN M.D., et al.: Long term detrimental effect of bile duct injury on health related quality of life. Arch. Surg., 139: 476-481, 2004.

2- CHUANG K.I.1, CORLEY D., POSTLETHWAITE D.A., MERCHANT M. and HARRIS H.W.: Does increased experience with laparoscopic cholecystectomy yield more complex bile duct injuries? Am. J. Surg. Apr., 203 (4): 480-7, 2012. doi: 10.1016/j.amjsurg.2011.08.018. Epub 2012 Feb 9, 2012.
3- BHARATY K.G.S. and NAGI S.S.: Post cholecystectomy bile duct injury and its squeal: Pathogenesis, classification, and management. Indian J. Gastroenterol., 33 (3): 201205,2014

4- WARGANTIWAR S.V., BYSANI P.R. and SHAH T.N.A. Study of 25 cases of CBD Injury Post Laparoscopic Cholecystectomy. International Journal of Science and Research (IJSR), 2 (9): 400-2, 2013.

5- FARAIDON F., TAYEB S., KARZAN S. and QALANDAR H.: Iatrogenic Bile Duct Injury Following Cholecystectomy, Surgical Management and Outcome: A Single Center Experience, Journal of Kurdistan Board of Medical Specialties, Vol. 4, No. 1, 2018.

6- AZIZ H., PANDIT V., JOSEPH B., JIE T. and ONG E.: Age and obesity are independent predictors of bile duct injuries in patients undergoing laparoscopic cholecystectomy. World J. Surg., 39: 1804-1808, 2015.

7- FULLUM T.M.1, DOWNING S.R., ORTEGA G., CHANG D.C., OYETUNJI T.A., VAN KIRK K., TRAN D.D., WOODS I., CORNWELL E.E. and TURNER P.L.: Is laparoscopy a risk factor for bile duct injury during cholecystectomy? JSLS. Jul-Sep., 17 (3): 365-70, 2013. doi: 10.4293/108680813X1365475453563 8.

8- JASON K., MELISSA S. CAMP, et al.: Surgical Management of Bile Duct Injuries Sustained During Laparoscopic Cholecystectomy Ann. Surg. May, 241 (5): 786-795, 2005.

9- THAMARA M., PERERA M.T., SILVA M.A., et al.: Specialist early and immediate repair of post-laparoscopic cholecystectomy bile duct injuries is associated with an improved long-term outcome. Ann. Surg., 253: 553-60, 2011.

10- DINDO D., DEMARTINES N. and CLAVIEN P.A.: Classification of surgical complications: A new proposal with evaluation in a cohort of 6336 patients and results of a survey. Ann. Surg., 240: 205-213, 2004.

11- BALZAN S., BELGHITI J., FARGEs O., et al.: The 5050 criteria on postoperative day 5: An accurate predictor of liver failure and death after hepatectomy. Ann. Surg., 242: 824-828, 2005.

12. FISCHER C.P., FAHY B.N., ALOIA T.A., et al.: Timing of referral impacts surgical outcomes in patients undergoing repair of bile duct injuries. HPB (Oxford), 11: 3237, 2009.

13-De PALMA G.D.1, PERSICO G., SOTTILE R., PUZZIELLO A., IULIANO G., SALVATI V., DONISI M., PERSICO F., MASTANTUONO L., PERSICO M. and MASONE S.: Surgery or endoscopy for treatment of postcholecystectomy bile duct strictures? Am. J. Surg. Jun., 185 (6): 532-5, 2003.

14- SCHMIDT S.C., LANGREHR J.M., HINTZE R.E. and NEUHAUS P.: Long term results and risk factors influencing outcome of major bile duct injuries following cholecystectomy. Br. J. Surg., 92 (1): 76-82, 2005.

15- MANNAN A., SOOMRO S.A., BHANBHRO R.J., GHAURI A., LAGHARI M.H. and SHAKIR: Common bile duct injury; management and outcome study at Isra University Hospital Hyderabad Sind. Professional Med. J., 22 (6): 818-822, 2015. 


\section{إصابات القنوات المرارية أثناء عملية

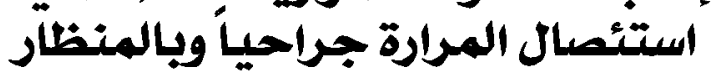

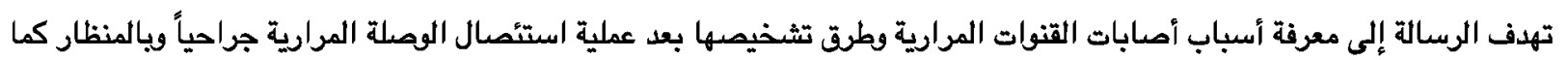

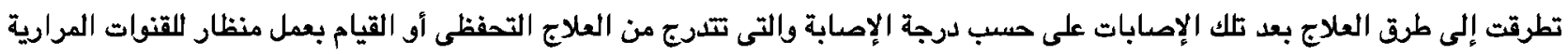
أو عمل جراحات إعادة توصيل القلاج بعد الإصات المرارية.

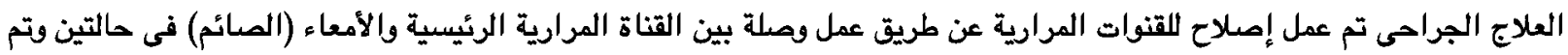

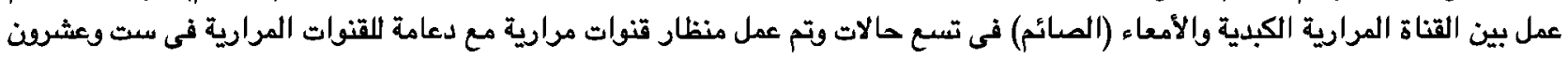

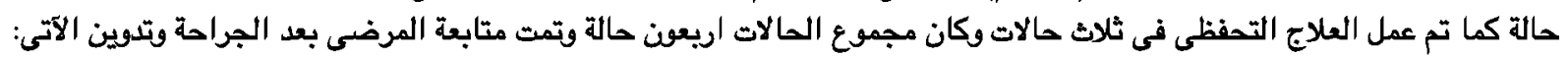
زمن الجراحة وحدوث مضاعفات بعد الجراحة مثل (ضيق بالقنوات المرارية، تسريب من لقنوات المرارية، ارتفاع نسبة الصفراء، حدوث

حالات وفاه).

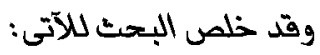

1- أهمية التشخيص المبكر لأصابات القنوات المرارية. r- تجنب حدوث تجمع للعصارة المراية داخل التجويف البروتونى. ז- أهمية تصوير القنوات المرارة قبل الشروع فى إعادة توصيلها . ع- استعمال الروية الآمنة أثناء تشريع قناة الحويصلة المرارية. 